\title{
Pharmacists' knowledge and perceptions regarding wound management at the community pharmacies in Jordan
}

\author{
Manal Ayyash ${ }^{1}$, Kamel Jaber ${ }^{2}$, Maram Abu Moghli ${ }^{3}$ Tareq L Mukattash ${ }^{4}$, Rana Abu Farha ${ }^{3 *}$ if \\ ${ }^{1}$ Department of Pharmaceutics and Pharmaceutical Science, Faculty of Pharmacy, Applied Science Private University, Amman, Jordan. \\ ${ }^{2}$ Faculty of Medicine, The University of Jordan, Amman, Jordan. \\ ${ }^{3}$ Department of Clinical Pharmacy and Therapeutics, Faculty of Pharmacy, Applied Science Private University, Amman, Jordan. \\ ${ }^{4}$ Department of Clinical Pharmacy, Faculty of Pharmacy, Jordan University of Science and Technology, Irbid, Jordan.
}

\begin{tabular}{|c|c|}
\hline ARTICLE INFO & ABSTRACT \\
\hline $\begin{array}{l}\text { Received on: } 23 / 04 / 2021 \\
\text { Accepted on: } 11 / 06 / 2021 \\
\text { Available online: } 05 / 08 / 2021\end{array}$ & $\begin{array}{l}\text { Community pharmacists play an important role by being a valuable resource in the management of the wound. In } \\
\text { this descriptive cross-sectional survey-based study conducted during October } 2020 \text {, we aimed to assess community } \\
\text { pharmacists' knowledge and perception regarding wound management at the community pharmacies in Jordan. Thus, } \\
\text { community pharmacists in Jordan have been invited to fill out an electronic-based survey. During the study period, }\end{array}$ \\
\hline $\begin{array}{l}\text { Key words: } \\
\text { Wound care, community } \\
\text { pharmacy, knowledge, } \\
\text { perception, pharmacists, } \\
\text { Jordan. }\end{array}$ & $\begin{array}{l}152 \text { community pharmacists participated in this study. Regarding participants' knowledge about wound management, } \\
\text { pharmacists showed good knowledge regarding the medications and conditions known to delay wound healing. } \\
\text { On the other hand, } 82.2 \% \text { reported a lack of adequate knowledge and adequate skills to deal with wounds. Finally, } \\
\text { results showed that male pharmacists showed a higher knowledge score about wound management compared to } \\
\text { females }(p=0.001) \text {. Those pharmacists who attended a course/workshop about wounds showed a significantly higher } \\
\text { knowledge score than those who did not }(p<0.001) \text {. In conclusion, our findings revealed that awareness campaigns } \\
\text { and educational workshops are needed to enhance pharmacists' knowledge and skills in this area. }\end{array}$ \\
\hline
\end{tabular}

\section{INTRODUCTION}

Professions exist to serve society. Therefore, the pharmacy profession plays an important role in patients' healthcare processes (Debjit et al., 2009). Pharmacists must upgrade their expertise in drug product orientation to clinical exposure to provide patient-oriented care (Debjit et al., 2009; Mukattash et al., 2018; Tumkur et al., 2012) and address the drug-related needs of society and individual patients (Hepler, 1985). The new professional practice model to patient care is being called pharmaceutical care and represents a significant transformation in the social responsibility of pharmacists. The most generally accepted definition of this new approach is "the responsible provision of drug therapy to achieve definite

\footnotetext{
${ }^{*}$ Corresponding Author

Rana Abu Farha, Department of Clinical Pharmacy and Therapeutics, Faculty of Pharmacy, Applied Science Private University, Amman, Jordan. E-mail:r_abufarha@asu.edu.jo
}

outcomes that improve a patient's quality of life" (Debjit et al., 2009; Hepler and Strand, 1990). It is a paradigmatic change that redefines the pharmacist's identity as a healthcare provider, which has the patient as the focus of practice (Dupotey and De Oliveira, 2009).

Wound care and wound management appear to be evolving as a discrete specialty. Currently, pharmacists played an essential role in this area (Stokes, 2004). Nowadays, many nonprescription wound care products are marketed for minor wounds, such as topical antibiotic agents to prevent infection and antiseptics from disinfecting the intact skin and sterile bandages to accelerate healing (Terrie, 2010). Products and advice on wound care are services consumers expect from community pharmacies (Stokes, 2004), and pharmacist knowledge is only one possible range of service quality indicators (Stokes, 2004).

Community pharmacists can play an important role by being a valuable resource in managing wounds (Abduelkarem et al., 2021). They represent an excellent source of information for individuals seeking guidance regarding nonprescription wound care products (Yvette and Terrie, 2006). They also need to 
recognize patients at high risk for wounds and poor wound healing and then educate and/or refer them appropriately (Jin, 2015).

The increasing involvement of pharmacists as the first port of call for many healthcare services, including the various wound care products recommended and advised by them (Abduelkarem et al., 2021), highlights the importance of screening the knowledge and the experience of community pharmacists in Jordan in the domain of wound care management. Thus, the study's main aim was to assess community pharmacists' knowledge and their perception regarding wound management at the community pharmacies in Jordan.

\section{METHODS}

\section{Study design, settings, and participants}

In this descriptive cross-sectional survey-based study conducted during October 2020, which targeted community pharmacists in Jordan, an appropriate sample size of pharmacists was invited to participate in the study survey by sending the survey link through social media platforms (Facebook and WhatsApp). The inclusion criterion was pharmacists who reside in Jordan, whereas the exclusion criterion was pharmacists with a diploma degree. Pharmacists were informed about the aim of the study and that filling the survey would take approximately 15 minutes. Also, they were asked to provide their electronic informed consent to participate in the study.

\section{Sample size calculation}

Based on Tabachnick and Fidell's (2006) recommendation for sample size calculation in multiple linear regression analyses used to assess factors affecting participants' knowledge about wound healing, 5-20 subjects per predictor were recruited. Using 20 subjects per predictor and since seven predictors were considered, a minimum sample size of 140 was appropriately representative.

\section{Survey instrument development and validation}

A validated questionnaire that measured pharmacists' knowledge, perception, and competence on wound healing was not available in the literature. Thus, a questionnaire was developed based on a literature review that required validation (Abduelkarem et al., 2012; Malaekah et al., 2020). Several experts tested the face and content validity of the questionnaire in clinical pharmacy. Experts' comments were collected and revised. Subsequently, some minor modifications were made to the questionnaire.

The questionnaire consisted of four sections with closeended, multiple-choice, and 5-point Likert scale statements. The first section consisted of questions that collect participants' demographics. The second section contained seven questions asking about participants' knowledge in wound healing, allowing multiple-choice selection questions. At the same time, the third section was designed for assessing pharmacists' perception toward their role in wound management at the community pharmacy through seven statements. The answers to these statements were on a 5-point Likert scale ranging from strongly agree to strongly disagree, while the last section aimed to evaluate the perceived barrier by community pharmacists to manage wounds at the community pharmacy using five statements that were assessed using a 5-point Likert scale ranging from strongly agree to strongly disagree.

\section{Measured outcome}

Participants gained one point for each correct answer and zero points for each incorrect answer for knowledge questions. For multiple-choice questions, they gained one point for each correctly checked or correctly nonchecked answer. Then, the total knowledge score was calculated out of 15 .

\section{Ethical consideration}

Ethics Committee provided institutional Review Board (IRB) approval at Applied Science Private University (Approval number: 2020-PHA-22). The participants were informed that their responses are anonymous, and their data will be kept confidential.

\section{Statistical analysis}

Data were entered and analyzed using the Statistical Package for the Social Sciences (SPSS), Version 25.0 (SPSS Inc., Chicago, IL). Categorical variables were presented as frequencies and percentages. Continuous variables were presented as means and standard deviations or medians and interquartile ranges depending on the normality of variables. The normality was tested by Kolmogorov-Smirnov test (with $p$-value $\geq 0.05$ indicating a normally distributed continuous variable).

Simple linear regression was carried out to initially screen the independent variables that affect participants' knowledge score about wound management. Variables that were found to have $p$-value $<0.25$ using univariate linear regression analysis were entered into multiple linear regression analysis. Variables were selected after checking their independence, where tolerance values $>0.1$ and variance inflation factor values $<5$ were selected to indicate the absence of multicollinearity between the independent variables in regression analysis. In the multiple linear regression analysis, variables that were independently affecting participants' knowledge about wound healing were identified. A $p$-value of $<0.05$ was considered statistically significant.

\section{RESULTS}

During the study period, 152 community pharmacists agreed to take part and participate in this study. The mean age of the participating pharmacists was $34.4(\mathrm{SD}=11)$ years and three-fourths of them were females $(n=113,74.3 \%)$. Among the recruited pharmacists, $21.1 \%(n=32)$ had a postgraduate degree (either master's or Ph.D. degree) and most of them are working in independent community pharmacies $(n=112,73.7 \%)$. More than half of the pharmacists worked in pharmacies located in commercial areas, and around $57.9 \%$ of them $(n=88)$ reported having less than 5 years of experience. For more details about demographic characteristics, refer to Table 1.

Regarding pharmacists' experience in wound management (Table 2), the majority of pharmacists $(n=130$, $85.8 \%$ ) reported that their primary expertise is to provide rudimentary care for wounds (basic first aids) and most of them ( $n$ $=142,93.4 \%$ ) reported that minor wounds are the main common type of wounds seen at their pharmacies. On the other hand, only $13.2 \%$ of the pharmacists $(n=20)$ believed that their pharmacies completely met the needs of the level of wound care service, and 
Table 1. Sociodemographic characteristics of the study sample $(n=152)$.

\begin{tabular}{|c|c|c|}
\hline Parameter & Mean (SD) & $n(\%)$ \\
\hline Age (years) & $34.4(11.0)$ & \\
\hline \multicolumn{3}{|l|}{ Gender } \\
\hline Males & & $39(25.7)$ \\
\hline Females & & $113(74.3)$ \\
\hline \multicolumn{3}{|l|}{ Educational level } \\
\hline Undergraduate level & & $120(78.9)$ \\
\hline Postgraduate level & & $32(21.1)$ \\
\hline \multicolumn{3}{|l|}{ Job status } \\
\hline Employee & & $104(68.4)$ \\
\hline Owner & & $48(31.7)$ \\
\hline \multicolumn{3}{|l|}{ Site of work } \\
\hline Independent community pharmacy & & $112(73.7)$ \\
\hline Chain community pharmacy & & $40(26.3)$ \\
\hline \multicolumn{3}{|l|}{ Location of pharmacy } \\
\hline Commercial area & & $79(52.0)$ \\
\hline Others (residential or clinics area) & & $73(48.0)$ \\
\hline \multicolumn{3}{|l|}{ Experience as community pharmacists } \\
\hline $1-5$ years & & $88(57.9)$ \\
\hline$>5$ years & & $64(49.1)$ \\
\hline \multicolumn{3}{|l|}{ Number of patients you service/day } \\
\hline Under 40 & & $65(42.8)$ \\
\hline$\geq 40$ & & $87(57.2)$ \\
\hline
\end{tabular}

Table 2. Community pharmacists' experience in wound management $(n=152)$.

\begin{tabular}{lc}
\hline Parameter & $\boldsymbol{n}(\mathbf{\%})$ \\
\hline What level of wound care service do you believe is provided at this \\
pharmacy? \\
$\quad$ Rudimentary (basic first aid only) & $130(85.8)$ \\
$\quad$ Advanced (treat complex chronic wounds) & $22(14.5)$ \\
Most common type of wound seen at the pharmacy & $142(93.4)$ \\
Minor wounds & $10(6.6)$ \\
$\quad$ Severe wounds & $35(23.0)$ \\
Do the space and facilities of this pharmacy meet the needs of the level of \\
wound care service provided at this pharmacy? \\
$\quad$ Needs not at all met & $97(63.8)$ \\
Needs partially met & $20(13.2)$ \\
Needs completely met & $63(41.4)$ \\
Have you ever attended a course/workshop about wound management? \\
Yes & $89(58.6)$ \\
\hline
\end{tabular}

only $41.4 \%$ of them $(n=63)$ have attended a course/workshop about wound management.

Pharmacists were asked about their sources of information regarding wound management (Fig. 1), and results showed that university courses were the main source of information $(n=115$,
$75.7 \%$ ), followed by information from colleagues or coworkers $(n=110,72.4 \%)$. Webinars $(n=55,36.2 \%)$ and books $(n=77$, $50.7 \%$ ) were the least reported sources for information among the participated pharmacists.

Regarding participants' knowledge about wound management (Table 3), pharmacists showed a good knowledge regarding the medications and conditions known to delay wound healing, where more than $50 \%$ of the participants were aware that the use of systemic steroids and immunosuppressant and the presence of autoimmune disease, diabetes, poor nutrition, and smoking were among the factors that may contribute to delaying wound healing.

Unfortunately, only $23 \%$ of the pharmacists $(n=35)$ recognized that maintaining warm and moist conditions is the critical factor for wound healing. In comparison, $53.0 \%$ of them ( $n=81)$ knew that a moisture-free environment is needed for diabetic, dry, gangrenous toes for adequate recovery. Finally, an overall mean knowledge score (out of 15$)$ was $9.6(\mathrm{SD}=2.0)$, which is considered a good knowledge score. For more details, refer to Table 3.

Regarding pharmacists' perceived attitude toward their role in wound management (Table 4$)$, the majority of them $(n=$ $133,87.5 \%$ ) believed that they would like to see increased and improved wound management training, and $79.0 \%$ of them $(n=$ 120) agreed/strongly agreed that formal license to the pharmacists is important to assure standards of professional excellence. Also, $71.7 \%$ of the participants $(n=109)$ thought that a professional fee should be applied to certain aspects of wound management in the pharmacy. For more details, refer to Table 4.

The barriers to managing a wound at the community pharmacy were assessed using five statements (Fig. 2). Lack of adequate knowledge and lack of sufficient skills to deal with wounds were the essential barriers revealed by the study participants $(n=125,82.2 \%)$, while fears from the wound $(n=$ 90, 59.1\%) were considered the least important factors were precluding pharmacists from providing wound management at their pharmacies.

Finally, linear regression analysis (Table 5) showed that males showed higher knowledge scores about wound management than females $(p=0.001)$. Also, those pharmacists who have attended a course/workshop about wound management are associated with a significantly higher knowledge score than those who did not $(p<0.001)$.

\section{DISCUSSION}

Pharmacists are increasingly participating in wound care and management; this results from more profound relationships between society and pharmacists. In addition, the growth in the number of pharmacies, pharmacists, and nonprescription/over the counter medications and remedies allows pharmacies to every so often be the go-to destination in mild-to-moderate cases where medical attention is needed. Wounds, cuts, and burns are included.

The majority of the pharmacists presented that their main source of information regarding the management of wounds came from university courses $(75.7 \%)$ and work colleges $(72.4 \%)$ and a decent percentage of information came from social media (Facebook for example) (71.1\%), while only a minority obtained their information from webinars $(36.2 \%)$. University courses and 


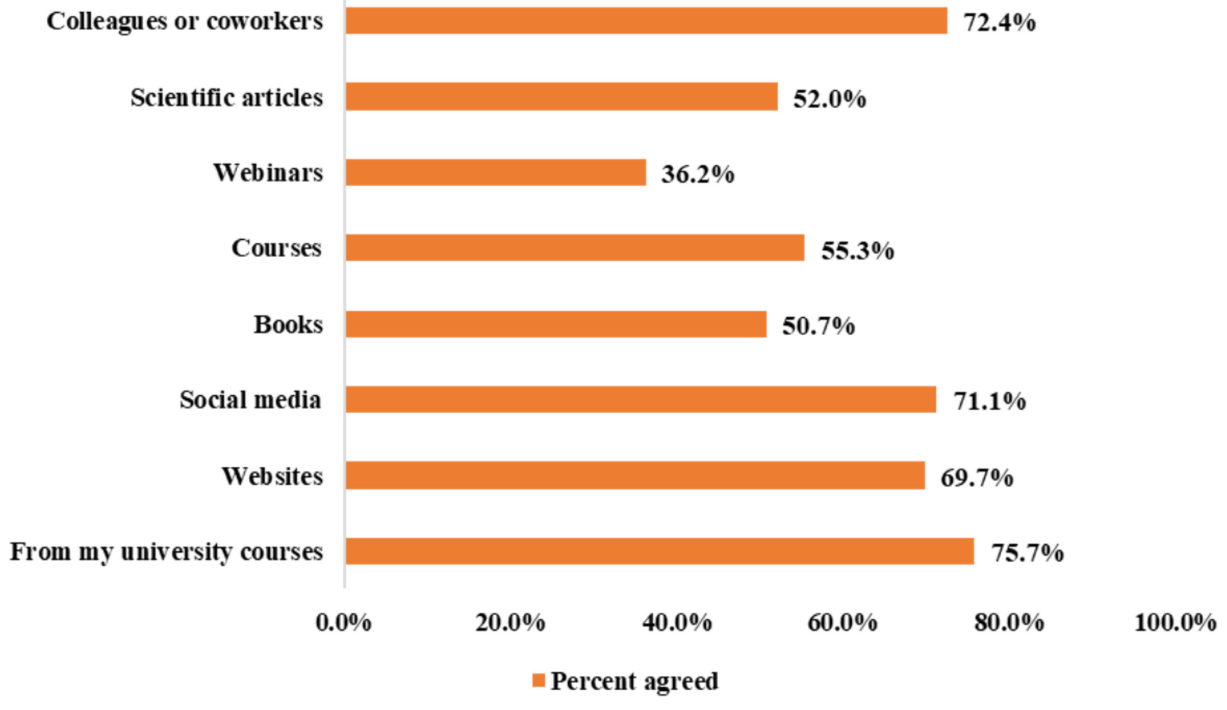

Figure 1. Source of information about wound management among the study sample $(n=152)$.

Table 3. Assessment of study participants' knowledge about wound management $(n=152)$.

\begin{tabular}{|c|c|}
\hline \multirow{2}{*}{ Parameter } & Correct answers \\
\hline & $n(\%)$ \\
\hline \multicolumn{2}{|c|}{ Which of the following medications are known to delay wound healing? } \\
\hline Use of systemic steroids ${ }^{a}$ & $105(69.1)$ \\
\hline Use of immunosuppressive drugs ${ }^{\mathrm{a}}$ & $116(76.3)$ \\
\hline Use of nonsteroidal anti-inflammatory ${ }^{\mathrm{a}}$ & $75(49.3)$ \\
\hline \multicolumn{2}{|c|}{ Which of the following conditions known to delay wound healing? } \\
\hline Rheumatoid arthritis ${ }^{\mathrm{a}}$ & $74(48.7)$ \\
\hline Autoimmune diseases ${ }^{\mathrm{a}}$ & $122(80.3)$ \\
\hline Poor nutrition ${ }^{\mathrm{a}}$ & $134(88.2)$ \\
\hline Diabetes $^{\mathrm{a}}$ & $147(96.7)$ \\
\hline Smoking ${ }^{\mathrm{a}}$ & $104(68.4)$ \\
\hline \multicolumn{2}{|l|}{ The key factor of wound management is to provide } \\
\hline Warm and moist conditions ${ }^{\mathrm{a}}$ & $35(23.0)$ \\
\hline \multicolumn{2}{|c|}{ Only diabetic, dry, gangrenous toes require a moisture-free environment for effective healing } \\
\hline True $^{a}$ & $81(53.3)$ \\
\hline \multicolumn{2}{|c|}{ When do you recommend and dispense an absorbent dressing while managing a wound } \\
\hline As a primary dressing ${ }^{a}$ & $101(66.4)$ \\
\hline As a secondary dressing ${ }^{\mathrm{a}}$ & $90(59.2)$ \\
\hline To prevent periwound area from being macerated ${ }^{a}$ & $124(81.6)$ \\
\hline As a first choice in radiation burn ${ }^{\mathrm{b}}$ & $68(44.7)$ \\
\hline \multicolumn{2}{|l|}{ The following photo represents a type of wound dressings } \\
\hline Hydrogels & $83(54.6)$ \\
\hline Knowedge score (mean (SD) & $9.6(\mathrm{SD}=2.0)$ \\
\hline
\end{tabular}

This choice is a correct choice.

${ }^{b}$ This choice is incorrect. 
Table 4. Pharmacists' perceived attitude toward their role in wound management $(n=152)$.

\begin{tabular}{|c|c|c|c|}
\hline \multirow[b]{2}{*}{ Statements } & \multicolumn{3}{|c|}{ Pharmacists' responses $n(\%)$} \\
\hline & $\begin{array}{c}\text { Strongly } \\
\text { agree/agree }\end{array}$ & Neutral & $\begin{array}{l}\text { Strongly } \\
\text { disagree/disagree }\end{array}$ \\
\hline I would like to see increased and improved wound management training & $133(87.5)$ & $16(10.5)$ & $3(2.0)$ \\
\hline A professional fee should be applied to certain aspects of wound management in the pharmacy & $109(71.7)$ & $36(23.7)$ & $7(4.6)$ \\
\hline Formal license to the pharmacists is important to assure standards of professional excellence & $120(79.0)$ & $28(18.4)$ & $4(2.6)$ \\
\hline Pharmacists have an important role in the diagnosis of wounds & $105(69.1)$ & $36(23.7)$ & $11(7.2)$ \\
\hline Pharmacies should only practice wound management, if a separate treatment area is available & $106(69.7)$ & $34(22.4)$ & $12(7.9)$ \\
\hline $\begin{array}{l}\text { Wound management is an opportunity to be involved, as a team with other healthcare professionals, like } \\
\text { doctors and nurses }\end{array}$ & $113(74.3)$ & $33(21.7)$ & $6(4.0)$ \\
\hline
\end{tabular}

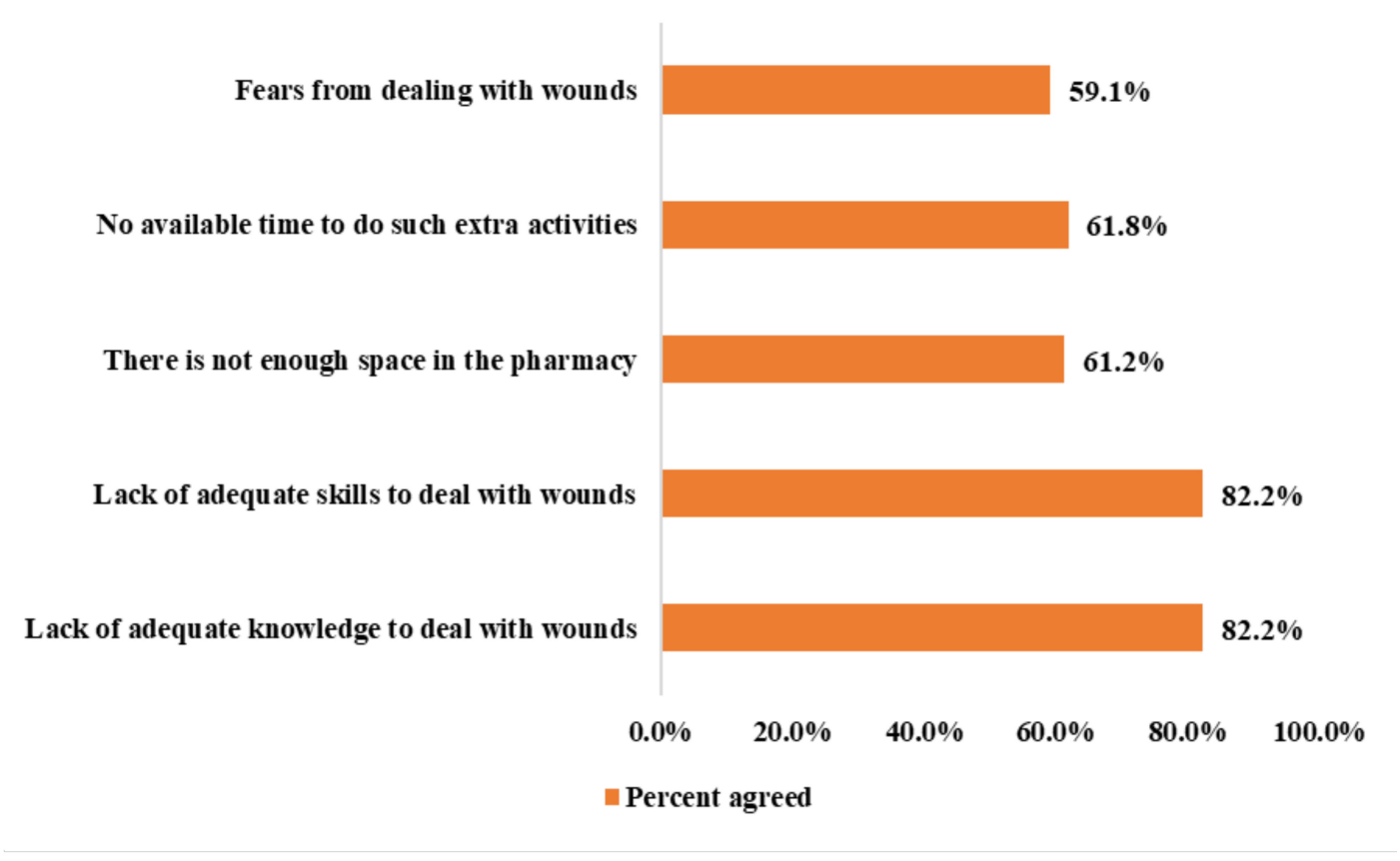

Figure 2. Perceived barriers by community pharmacists to manage wounds at the community pharmacy $(n=152)$.

colleges are considered good sources as they come from reliable books (Tez and Yildiz, 2017), although they are not immune to faults. It is concerning the percentage of pharmacists taking such vital information from social media platforms, which mostly do not provide any references to their sources of information, leading to very low accuracy (Tonsaker et al., 2014). On the other hand, webinars and courses held by up-to-date professionals should receive more emphasis as they introduce the latest guidelines and practice techniques and are easier to access for many healthcare providers (Matza et al., 2015).

Results revealed that more than half of the participants knew about the importance of systemic steroids (69.1\%) and immunosuppressants $(76.3 \%)$ in delaying wound healing. Regrettably, less than half (49.3\%) of the participants recognized the importance of NSAIDs in having depressant effects on wound healing. NSAIDs are commonly used because of their superior analgesic and anti-inflammatory effects and are sensibly prescribed with painful wounds, although they simultaneously block PGE2 (important healing mediators) production (Anderson and Hamm, 2014).
The results also prevailed that more than half $(51.3 \%)$ of participants were not aware of the consequences of rheumatoid arthritis in delaying wound healing (Vickers, 2004). Pharmacists should be more aware of this point to further aid patients through counseling. On the contrary and luckily, of course, a very high percentage $(96.7 \%)$ of the pharmacists in the study knew the consequences of diabetes on wound healing, possibly pertaining to the high prevalence of diabetes in Jordan and worldwide (WHO, 2016).

Remarkably, a very small number $(23 \%)$ of the participants were conscious about the favorable environment for wound healing, warm, and moist. Warm and moist conditions are important to prevent dehydration of the wounded area and aid in cell regeneration (Junker et al., 2013).

According to the study researchers, the mean knowledge score for the study participants was 9.6 out of 15 , which is considered "good." Pharmacists' knowledge and skills in wound management might improve in accordance with the perceived positive attitude of pharmacists despite the massive workload pharmacists faced. Pharmacists' skills in wound care require 
Table 5. Assessment of factors affecting participants' knowledge about wounds management $(n=152)$.

\begin{tabular}{|c|c|c|c|c|}
\hline \multirow{2}{*}{ Parameter } & \multicolumn{4}{|c|}{ Knowledge score } \\
\hline & Beta & $p$-value ${ }^{a}$ & Beta & $p$-value ${ }^{\mathrm{b}}$ \\
\hline Age (years) & 0.070 & 0.394 & - & - \\
\hline \multicolumn{5}{|l|}{ Gender } \\
\hline Female & Reference & & & \\
\hline Male & 0.303 & $<0.001$ & 0.248 & $0.001^{*}$ \\
\hline \multicolumn{5}{|l|}{ Educational level } \\
\hline Undergraduate level & Reference & & & \\
\hline Postgraduate level & -0.148 & 0.068 & -0.124 & 0.094 \\
\hline \multicolumn{5}{|l|}{ Job status } \\
\hline Employee & Reference & & & - \\
\hline Owner & 0.023 & 0.775 & - & \\
\hline \multicolumn{5}{|l|}{ Site of work } \\
\hline Independent community pharmacy & Reference & & & - \\
\hline Chain community pharmacy & 0.031 & 0.708 & - & \\
\hline \multicolumn{5}{|l|}{ Location of pharmacy } \\
\hline Commercial area & Reference & & & \\
\hline Others (residential or clinics area) & 0.089 & 0.277 & - & - \\
\hline \multicolumn{5}{|l|}{ Experience as community pharmacists } \\
\hline $1-5$ years & Reference & & & \\
\hline$>5$ years & 0.079 & 0.334 & - & - \\
\hline \multicolumn{5}{|c|}{$\begin{array}{l}\text { Have you ever attended a course/workshop about wound } \\
\text { management? }\end{array}$} \\
\hline Yes & Reference & & & \\
\hline No & -0.354 & $<0.001$ & -0.300 & $<0.001^{*}$ \\
\hline
\end{tabular}

the availability of certain conditions, such as formal licensing, implying a professional fee, creating a separate treatment area, and improved training, as the majority $(82.2 \%)$ of pharmacists mentioned that the lack of adequate knowledge and adequate skills were the main barriers.

Results of this study showed that gender was considered one of the significant factors in the level of knowledge in wound management, as males are more resilient and able to withstand graphic scenes (Boardman et al., 2008); this finding was comparable to other studies carried out abroad including Sweden (Fredrikson et al., 1996) and India (Wani et al., 2014). Moreover, the results proved that the more training (courses/workshops) the pharmacists had, the more knowledge they possessed regarding wound care (Gray et al., 2019).

Our results also showed that holding a higher educational degree could have been an important factor in the level of knowledge among pharmacists. Still, unfortunately, multiple linear regression ruled out this relationship. However, it is predictable that having more postgraduates included in the sample or having a larger sample size probably would have shown a direct relationship between these two factors.

Even though this study represents the first study in Jordan to evaluate the knowledge and perception about wound management among Jordanian pharmacists, we still are aware of the main methodological limitation of this study. As the study relied on the self-administered questionnaire, which may overestimate pharmacists' perception of their role in wound management.

\section{CONCLUSION}

In conclusion, our findings revealed a positive perception of pharmacists' role in wound care among the community pharmacists in Jordan. Male pharmacists and those with received previous training showed higher knowledge scores about wound management compared to others. Lack of adequate knowledge and lack of sufficient skills to deal with wounds were the essential barriers revealed by the study participants to deal with wounds. Hence, awareness campaigns and educational workshops are needed to enhance pharmacists' knowledge and skills in this area.

\section{AUTHORS' CONTRIBUTIONS}

All authors of this study have contributed to the idea conception, data collection, data analysis, and writing the article and all agreed to be accountable for all aspects of the work.

\section{FUNDING}

There is no funding to report. 


\section{CONFLICTS OF INTEREST}

The authors report no financial or any other conflicts of interest in this work.

\section{ETHICAL APPROVALS}

Ethics Committee provided institutional Review Board (IRB) approval at Applied Science Private University (Approval number: 2020-PHA-22). The participants were informed that their responses are anonymous, and their data will be kept confidential.

\section{PUBLISHER'S NOTE}

This journal remains neutral with regard to jurisdictional claims in published institutional affiliation.

\section{REFERENCES}

Abduelkarem A, Dada M, Sharif S. The provision of wound management services by community Pharmacists in Dubai, United Arab Emirates. Jordan J Pharm Sci, 2012; 5:194-202.

Anderson K, Hamm RL. Factors that impair wound healing. J Am Coll Clin Wound Spec, 2014; 4(4):84-91.

Boardman JD, Blalock CL, Button TMM. Sex differences in the heritability of resilience. Twin Res Hum Genet, 2008; 11(1):12-27.

Debjit B, Chiranjib B, Jitender Y, Chandira M. Role of community pharmacist in management and prevention diabetic foot ulcer and infections. J Chem Pharm Res, 2009; 1(1):38-53.

Dupotey NMV, De Oliveira DR. A qualitative glimpse at pharmaceutical care practice. Pharm World Sci, 2009; 31(6):609.

Fredrikson M, Annas P, Fischer H, Wik G. Gender and age differences in the prevalence of specific fears and phobias. Behav Res Ther, 1996; 34(1):33-9.

Gray TA, Wilson P, Dumville JC, Cullum NA. What factors influence community wound care in the UK? A focus group study using the Theoretical Domains Framework. BMJ Open, 2019; 9(7):e024859.

Hepler CD. Pharmacy as a clinical profession. Am J Hosp Pharm, 1985; 42(6):1298-306.

Hepler CD, Strand LM. Opportunities and responsibilities in pharmaceutical care. Am J Hosp Pharm, 1990; 47(3):533-43.

Jin S. Day in the life: a pharmacist's role in wound care. The wound management team. Wound Care Can, 2015; 13(2):34-7.

Junker JPE, Kamel RA, Caterson EJ, Eriksson E. Clinical impact upon wound healing and inflammation in moist, wet, and dry environments. Adv Wound Care, 2013; 2(7):348-56.
Malaekah HM, Alotaibi AE, Alsebail RA, Alelawi GT, Alsarrani RH, Banjar WM. Wound care knowledge and perception of the Saudi general population in Riyadh Region. Adv Wound Care, 2020; 10(6):293300; doi:10.1089/wound.2020.1210

Matza AR, Sloan CA, Kauth MR. Quality LGBT health education: a review of key reports and webinars. Clin Psychol Sci Pract, 2015; 22(2):127-44.

Mukattash TL, Bazzi NH, Nuseir KQ, Jarab AS, Abu-Farha RK, Khdour MR. Pharmaceutical care in community pharmacies in Jordan: a public survey. Pharm Pract, 2018; 16(2):1126.

Stokes J. Wound care benchmarking in community pharmacy: piloting a method of QA indicator development/[Dr Julie Stokes]. Pharmacy Guild of Australia, Canberra, Australia, 2004.

Tabachnick BG, Fidell LS. Using multivariate statistics. 5th edition. Allyn \& Bacon Inc, Boston, MA, 2006.

Terrie YC. First aid products for wound care. Pharm Times, 2010; 76(5):23

Tez M, Yildiz B. How reliable are medical textbooks? J Grad Med Educ, 2017; 9(4):550.

Tonsaker T, Bartlett G, Trpkov C. Health information on the Internet: gold mine or minefield? Can Fam Physician, 2014; 60(5):407-8.

Tumkur A, Muragundi P, Naik A, Shetty R. Pharmaceutical care: need of the hour in India. J Young Pharm, 2012; 4(4):282-6.

Vickers A. Delayed wound healing in patients with rheumatoid arthritis. Nurs Times, 2004; 100(14):61.

Wani AL, Ara A, Bhat SA. Blood injury and injection phobia: the neglected one. Behav Neurol, 2014; 2014:471340.

WHO. Web World Health Organization-diabetes country profiles: diakses. WHO, Geneva, Switzerland, 2016.

Yvette C. Terrie B. A pharmacist's guide to OTC therapy: wound care. Pharmacy Times, 2006.

\section{How to cite this article:}

Ayyash M, Jaber K, Moghli MA, Mukattash TL, Farha RA. Pharmacists' knowledge and perceptions regarding wound management at the community pharmacies in Jordan. J Appl Pharm Sci, 2021; 11(08):036-042. 